\title{
Da relação com o saber às identidades da educação física: narrativas de estudantes do Ensino Médio $^{12}$
}

\section{From the relationship with knowledge to identities of physical education: narratives of students in the High School}

\author{
Wagner dos Santos (i) \\ Verônica Freitas dos Santos (ii) \\ Jean Carlos Freitas Gama (iii) \\ Sayonara Cunha de Paula (iv) \\ Juliana Martins Cassani (v) \\ (i) Universidade Federal do Espírito Santo - UFES, Vitória, ES, Brasil. https://orcid.org/0000-0002- \\ 9216-7291, wagnercefd@gmail.com. \\ (ii) Universidade Federal do Espírito Santo - UFES, Vitória, ES, Brasil. https://orcid.org/0000-0002- \\ 3618-5110,petitvell@gmail.com. \\ (iii) Universidade Federal do Espírito Santo - UFES, Vitória, ES, Brasil. https://orcid.org/0000-0002- \\ 7116-4323, jeanfreitas.gama@gmail.com. \\ (iv) Universidade Federal do Espírito Santo - UFES, Vitória, ES, Brasil. https:/ /orcid.org/0000-0002- \\ 7195-4085, sayocpaula@gmail.com. \\ (v) Universidade Federal do Espírito Santo - UFES, Vitória, ES, Brasil. https://orcid.org/0000-0001- \\ 6332-7930,julianacassani@gmail.com.
}

\section{Resumo:}

Este artigo objetiva compreender as relações que os alunos estabelecem com os saberes nas aulas de educação física e suas implicações para a constituição das identidades desse componente curricular. Analisa as narrativas autobiográficas de alunos do $3^{\circ}$ ano do Ensino Médio sobre os diferentes modos de apropriação do seu processo de escolarização com a educação física. Utiliza narrativas orais e imagéticas dos estudantes como fontes. Os resultados mostraram que a relação com o saber e as identidades da educação física produzidas é tensionada pela lógica escolar e pelas experiências, o que resulta na perda do seu interesse nas aulas ao decorrer do processo de escolarização.

Palavras-chave: educação física, Ensino Médio, saberes, narrativas

\footnotetext{
${ }^{1}$ Apoio: Coordenação de Aperfeiçoamento de Pessoal de Nível Superior (Capes).

${ }^{2}$ Normalização, preparação e revisão textual: Douglas Mattos (Tikinet) - revisao@tikinet.com.br 


\begin{abstract}
:
It aims to understand the relationships that students establish with the knowledge in the classes of physical education and its implications for the constitution of the identities of this curricular component. It analyzes the autobiographical narratives of students of the 3rd year of High School on the different ways of appropriating their schooling process with physical education. Uses oral and imagery narratives of students as sources. The results showed that the relationship with the knowledge and the identities of physical education produced are strained by the school logic and the experiences, which results in the loss of their interest in the classes during the schooling process.
\end{abstract}

Keywords: physical education, High School, learning, narrative

\title{
Introdução
}

Objetivamos compreender as relações com os saberes (Charlot, 2000) que um grupo de alunos do ensino médio estabelece nas aulas de educação física (EF) na Educação Básica, a partir das suas experiências (Dewey, 1978) e suas implicações para a constituição das identidades (Hall, 2000) desse componente curricular. Compreendemos que tanto os saberes como as identidades se apresentam imbricados, pois são construções sociais historicamente produzidas.

Em estudo anterior (Santos et al., 2014), ao analisarmos o que os alunos do Ensino Médio aprenderam na EF durante o seu processo de escolarização, notamos que questões como a competição, repetição de conteúdos, gênero, supremacia do esporte, importância e utilidade dos aprendizados surgiram como fatores determinantes no interesse em aprender os saberes compartilhados durante as aulas.

$\mathrm{Na}$ compreensão dessas tensões, identificamos que os estudantes atribuem sentidos e valores diferentes às experiências de aprendizagem de acordo com o período da vida escolar que estão narrando. Esses distintos sentidos criados para a EF constituem-se em identidades que se modificam à medida que os alunos avançam no processo de escolarização, influenciando diretamente o que eles escolhem aprender ou não na disciplina.

Sobre as pesquisas realizadas com o Ensino Médio, encontramos aquelas que se centram nos alunos, buscando apreender suas percepções de escola e escolarização (Brandolin, Koslinski, \& Soares, 2015; Fabri, Rossi, \& Ferreira, 2016; Pereira \& Lopes, 2016). No entanto, 
ainda são tímidos os estudos que dialogam com diferentes produções desses sujeitos na correlação com os sentidos atribuídos por eles aos processos de escolarização (Reis, 2012; Santos et al., 2016). Ou seja, faz-se necessário investigar as experiências dos alunos, abertos a ouvir e compreender suas perspectivas sobre os seus processos de aprendizagem, de modo a torná-los protagonistas de suas próprias histórias.

Nesse sentido, parece-nos importante indagar: quais são as identidades construídas pelos alunos sobre o componente curricular educação física no Ensino Médio? Como se dá tal processo, levando em consideração a diversidade de práticas produzidas pela escola?

Nesse caso, percebemos a relevância de analisar essas práticas com base em um deslocamento de olhar que nos permita novas interpretações sobre o modo como os alunos produzem sentidos sobre suas experiências de escolarização nas aulas de EF, bem como sobre as identidades construídas nas relações estabelecidas com os saberes.

Tal movimento se dá por meio de uma inversão metodológica, na qual o foco do pesquisador se dirige ao diálogo com os alunos e com as suas experiências, dando voz às suas diferentes identidades, tendo como referência uma diversidade de fontes (desenhos, cartazes, imagens e teatralização) que, por nós, foram interpretadas como narrativas. Elas, por sua vez, foram analisadas não como dados, mas como produções, consequência da ação cultural vivenciada pelos discentes nos lugares e espaços da instituição escolarizada.

\section{Teoria e método}

Assumimos como abordagem teórico-metodológica a teoria da relação com saber (Charlot, 2000), os conceitos de identidade (Hall, 2000) e experiência (Dewey, 1978), utilizando a narrativa autobiográfica (Souza, 2006). Para Charlot (2000),

a relação com o saber é relação com o tempo. A apropriação do mundo, a construção de si mesmo, a inscrição em uma rede de relações com os outros - "o aprender" - .... Analisar a relação com o saber é estudar o sujeito confrontado com a obrigação de aprender, em um mundo que ele partilha com os outros. (pp. 78-79) 


\section{pro.posıções}

$e$-ISSN 1980-6248

http://dx.doi.org/10.1590/1980-6248-2019-0074

O autor enfatiza as diversas formas pelas quais os sujeitos que compõem a sociedade aprendem a se relacionar com os mais variados saberes que lhes são compartilhados e deles se apropriarem, pois para ele, "nascer é ingressar em um mundo no qual estar-se-á submetido à obrigação de aprender. Ninguém pode escapar dessa obrigação, pois o sujeito só pode 'tornarse' apropriando-se do mundo" (Charlot, 2000, p. 59).

Assim, a produção de sentidos - e representação do que é aprendido ou não por parte dos alunos - está diretamente ligada ao tipo de relação estabelecida com os saberes a eles apresentados, saberes que se materializam no que o autor denomina de figuras do aprender. Para ele, as figuras são maneiras de aprender e, consequentemente, apropriar-se do mundo. Esse tipo de apropriação de saberes se apresenta ao sujeito sob três formas: (i) saberes-objeto (contidos em objetos como um livro, um jornal, um filme etc.); (ii) saberes de dominio (inscritos no corpo, nas práticas e em atividades a serem dominadas); (iii) saberes relacionais (inseridos nos relacionamentos, no contato com o outro).

Para Hall (2000), a identidade é construída nas diferenças e nas singularidades dos indivíduos. Ela surge "de uma falta de inteireza que é 'preenchida' a partir de nosso exterior, pelas formas através das quais nós imaginamos ser vistos por outros” (p. 39).

Para Dewey (1978), a experiência se dá de diferentes maneiras nas fases de desenvolvimento do sujeito, ela é uma fase da natureza onde situação e agente interagem e são modificados. Para ele, "a experiência educativa é, pois, essa experiência inteligente, em que participa o pensamento, através do qual se vêm a perceber relações e continuidades antes não percebidas" (p. 17).

Já a narrativa autobiográfica é compreendida como a arte de evocar, narrar e atribuir sentidos às experiências. Além disso, sua ação permite, pela exteriorização do conhecimento sobre si e das diversas dimensões dos saberes e fazeres pedagógicos, construir um processo de reflexão e interpretação das histórias de vida e dos percursos de apropriação dos saberes do narrador.

Narrar as experiências nas aulas de EF é também uma atividade de resgate da memória por meio da linguagem, inclusive a corporal, que propicia uma reflexão sobre as suas experiências e aprendizados inscritos em seu corpo. 


\section{pro.posições}

$e$-ISSN 1980-6248

A narrativa possibilita, ainda, o autoconhecimento, ao propiciar ao narrador papel de protagonista da sua própria história. Assim,

partir dos alunos, da sua fala e do seu corpo, em vez de focar a reflexão sobre o professor e o que ele ensina, constitui uma ruptura epistemológica fundamental. O ponto de partida não é mais o ensinar, ou seja, o que pretende a educação física, mas, sim, o aprender, isto é, o que está acontecendo quando um aluno participa das atividades. (Charlot, 2009, p. 240)

Convidamos para participar do estudo uma instituição pública de Ensino Médio, localizada no município da Serra/ES. A escolha deve-se ao fato de já termos realizado pesquisas anteriores na mesma escola (Santos et al., 2014; Vieira, Santos, \& Ferreira Neto, 2012).

No momento do levantamento das fontes, a escola possuía uma turma de $3^{\circ}$ ano do Ensino Médio com 13 alunos (9 meninas e 4 meninos). Assumimos como critérios de escolha dos alunos: ser da turma; e concordar com a participação no estudo. Com o consentimento de todos os estudantes, realizamos sete encontros para a elaboração das narrativas orais, imagéticas, escritas e corporais. Especificamente para essa pesquisa, foram utilizadas as narrativas orais e imagéticas, conforme destacado no Quadro 1.

Também no Quadro 1, sistematizamos as etapas da pesquisa com a identificação e o modo de produção das fontes. Nele apresentamos o envolvimento dos alunos em cada etapa da pesquisa. Os espaços não demarcados com $\mathrm{X}$ indicam ausência do aluno no dia em que determinado recurso metodológico foi realizado.

Quadro 1 - Participantes da pesquisa

\begin{tabular}{|c|c|c|c|c|}
\hline \multirow{2}{*}{ Aluno } & \multirow{2}{*}{ Idade } & \multicolumn{3}{|c|}{ Fontes de pesquisa } \\
\cline { 3 - 5 } & & Narrativas orais & Elaboração de cartaz & Elaboração corporal \\
\hline Rafaela & 16 & $\mathrm{X}$ & $\mathrm{X}$ & $\mathrm{X}$ \\
\hline Karen & 17 & $\mathrm{X}$ & $\mathrm{X}$ & $\mathrm{X}$ \\
\hline Jorge & 16 & $\mathrm{X}$ & $\mathrm{X}$ & $\mathrm{X}$ \\
\hline Paulo & 17 & $\mathrm{X}$ & $\mathrm{X}$ & $\mathrm{X}$ \\
\hline Leandro & 17 & $\mathrm{X}$ & $\mathrm{X}$ & $\mathrm{X}$ \\
\hline Fernanda & 16 & $\mathrm{X}$ & $\mathrm{X}$ & $\mathrm{X}$ \\
\hline Samanta & 16 & $\mathrm{X}$ & $\mathrm{X}$ & \\
\hline Bianca & 18 & $\mathrm{X}$ & $\mathrm{X}$ & $\mathrm{X}$ \\
\hline Helson & 17 & $\mathrm{X}$ & $\mathrm{X}$ & \\
\hline Carla & 17 & $\mathrm{X}$ & $\mathrm{X}$ & $\mathrm{X}$ \\
\hline Catarina & 17 & $\mathrm{X}$ & $\mathrm{X}$ & \\
\hline Daniela & 17 & $\mathrm{X}$ &
\end{tabular}

${ }^{3}$ Foram atribuídos nomes fictícios para preservar a identidade dos discentes 
Para captar os saberes compartilhados pelas/nas aulas de EF, foi necessário ampliar as possibilidades metodológicas levando em consideração a especificidade dos saberes que constituem esse componente curricular. Charlot (2009) sinaliza as dificuldades que os alunos têm ao narrar aprendizados inscritos em seu corpo. Nesse sentido, é preciso mobilizar alternativas metodológicas para potencializar a expressão dessas aprendizagens, na mediação entre o falar de e o fazer com, em uma ação que valorize o modo como o aluno se relaciona com o saber e, portanto, produz significado nas experiências com a EF durante a escolarização.

$\mathrm{Na}$ narrativa oral, o cotidiano ganha forma de linguagem e as imagens traduzem formas de ser e viver. Assim, memórias, histórias e narrativas refletem e retratam o mundo cotidiano, criado na experiência e recriado na rememoração. Nesse caso, em um primeiro momento, solicitamos aos alunos trazerem imagens que remetessem à época e a acontecimentos em que estabeleciam relação com o que era narrado.

Partindo disso, em uma segunda etapa, propomos a elaboração de um cartaz que representasse a história de cada um com a disciplina. Nesse momento puderam criar composições de colagens, desenhos e legendas sobre o que julgavam relevante expressar em relação a suas experiências. Entendemos que a produção de imagens narrativas (Pérez, Tavares, \& Araújo, 2009) atua como potencializador da rememoração.

As fontes foram captadas e tabuladas e, após leitura prévia, foram categorizadas em dois eixos, a saber: (i) onde e como o aluno aprende nas aulas de EF; e (ii) o que o aluno faz com o que aprende nas aulas.

Os alunos assinaram o Termo de Assentimento Livre e Esclarecido e as suas famílias o Termo de Consentimento, autorizando o uso dos registros produzidos para a pesquisa, conforme previsto pelo Comitê de Ética da Universidade Federal do Espírito Santo, aprovada sob o Processo no 15419913.4.0000.5542. 


\section{pro.posıções}

$e$-ISSN 1980-6248

http://dx.doi.org/10.1590/1980-6248-2019-0074

\section{Onde e como o aluno aprende nas aulas de EF?}

O primeiro movimento de análise evoca as narrativas dos alunos, as quais se sobressaíram na relação entre o que e como aprendem e o espaço onde esse aprendizado se constrói. As narrativas sobre o período inicial da escolarização (Fundamental I) ressaltam como os alunos se sentiam nas aulas. Karen destaca "no primário? A gente corria, brincava. Era aula para brincar". Paulo complementa, "ah, no Ensino Fundamental é difícil. Nessa época, eu só aprendi a jogar bola como queria. Era lazer! Aula de descer no escorregador!"”.

É interessante notar que, apesar de reconhecerem os jogos e brincadeiras como conteúdos ensinados na EF, os alunos afirmam que não houve aprendizado significativo, como destaca Leandro: "eles chamavam a EF de recreação nessa época, só brincava. Aprendi brincadeira. É só brincar, nem é coisa para aprender isso".

Portanto, nesse período o que prevalece para os estudantes é a representação de uma EF que se assemelha aos momentos de recreio e lazer (Würdig, 2010), diferentemente das outras disciplinas, as quais já têm algumas exigências avaliativas e demandam, na visão dos alunos, a apropriação de saberes-objeto para que possam ter um bom desempenho.

A identidade criada pelos alunos para a EF escolar nos anos iniciais no Ensino Fundamental está fortemente relacionada à ideia do lazer e atribuída também às características institucionalizadas para espaços que contemplem esse tipo de prática, como, por exemplo, o horário do recreio, aulas livres, passeios e momentos de recreação, pois são oportunidades que retiram o aluno da sala e promovem, na maioria das vezes, práticas corporais.

Se por um lado, no Ensino Fundamental $\mathrm{I}$, as aulas se associam às brincadeiras, no Ensino Fundamental II, percebemos uma transição não só de conteúdos, mas também da produção de sentidos sobre como e onde o aluno aprende. Carla, Karen e Helson associam os conhecimentos aprendidos na sala como teóricos, já aqueles aprendidos fora desse espaço se relacionam a conhecimentos práticos. Conforme esclarecem,

$\mathrm{Na}$ sala, a professora passava basicamente as regras do vôlei, pelo menos isso eu aprendi ... E fora da sala, tinha as coisas práticas que, tirando a dança, eu não aprendi nada. (Carla)

Se a aula de EF for dentro da sala, eu fico triste; se for fora, eu fico feliz! ... Podendo jogar um vôlei, eu vou ficar dentro da sala escrevendo? Nem parece EF. Ela está aqui é para tirar o aluno da sala. (Karen) 


\section{pro.posıções}

$e$-ISSN 1980-6248

http://dx.doi.org/10.1590/1980-6248-2019-0074

A gente tinha duas professoras. Com uma professora, a gente ia para a quadra e a outra era para passar dever. A gente odiava essa do dever, né? Era horrível ter aula para dever. (Helson)

Existe um claro estranhamento nas narrativas dos alunos quando as aulas são desenvolvidas na sala, como se não fosse algo característico da disciplina, como se EF só fosse "física" quando está fora do espaço da sala de aula. Nesse período, as narrativas apontam para o início de diversas tensões com a disciplina, principalmente a respeito das mudanças na prática pedagógica e nas exigências avaliativas.

As narrativas sinalizam para um conflito entre a identidade criada para a disciplina (no período anterior) e as experiências com uma EF que está mais próxima da lógica escolar e das demais matérias. Essa EF possui um conteúdo sistematizado, avalia com mais rigidez e tem momentos de aula realizada em sala, nos quais começa a se destacar, além da necessidade de dominar uma atividade, a necessidade de se construir enunciados sobre ela, compreender e criar regras e associar o conhecimento teórico e prático dos conteúdos da disciplina, resultando em um estranhamento e rejeição por parte dos estudantes.

Charlot (2009) provoca os educadores ao questionar onde está o "físico" da EF escolar? $\mathrm{O}$ autor argumenta que os educadores têm buscado uma significação da EF numa tentativa equivocada de adequação da disciplina à lógica de ensino da escola, sem levar em consideração, por exemplo, as identidades (e não a identidade) que transitam nesse contexto e os corpos que praticam a disciplina.

As especificidades da EF se mostram nas apropriações, sobretudo, dos saberes de domínio e dos saberes relacionais (Charlot, 2000) inscritos e aprendidos no/com o corpo ${ }^{4}$. Entretanto, é importante pontuar que os saberes-objeto também fazem parte dos conteúdos e aprendizagens da EF, uma vez que o corpo é, por nós, compreendido como algo que não se fragmenta entre físico e intelecto.

Dewey (1978), ao falar dos processos educacionais, apresenta-nos o corpo em sua concepção de "educação como reconstrução da experiência". Para ele, o processo da experiência envolve interações entre o eu e o outro, e isso gera outras situações, assim, "aí está o início do

\footnotetext{
${ }^{4}$ Charlot (2000) define como saber de domínio "atividades a serem dominadas, de estatuto variado: ler, nadar, desmontar um motor", e como saberes-relacionais os meios "e formas relacionais das quais se devem apropriar, quer se trate de agradecer, quer iniciar uma relação amorosa" (p. 66).
} 
processo de 'aprender por experiência', o que requer 'vida', experiência e aprendizagem”' (p. 16), de maneira indissociável.

A concepção de corpo aqui posta não remete apenas a um "corpo-máquina" e dicotômico em sua essência, entendemos o corpo como sendo de um sujeito encarnado em um mundo, ou, como destaca Charlot (2009) ao refletir sobre a obra de Merleau-Ponty, "uma consciência encarnada". Assim, a ideia de um "corpo vivencial" ou "corpo experiencial" nos faz pensar "em uma multidimensionalidade de nossa experiência corporal" (Najmanovich, 2001, p. 24).

Ao dialogarmos com Najmanovich (2001) e com o próprio Charlot (2009), entendemos que fica clara a concepção desenvolvida por Merleau-Ponty e que culmina na máxima "eu sou meu corpo". Assim, para nós, o corpo é o corpo-sujeito, unificado e com uma linguagem específica de aprendizagens, adaptações e ressignificações. "Com efeito, se 'eu sou meu corpo', quem ‘sabe' o que é o corpo e como se pode educá-lo, é esse eu-sujeito-encarnado e, portanto, junto a ele é que se devem procurar as informações a respeito dos efeitos da EF” (Charlot, 2009, p. 240), levando em consideração a complexidade das apropriações/maneiras de relacionar-se com o saber e das experiências da vida "vivida" (Dewey, 1978).

Por mais que os estudantes tenham dificuldade em narrar seus aprendizados inscritos no corpo em forma de enunciado, eles identificam que os saberes com os quais a $\mathrm{EF}$ trabalha diferenciam-se dos saberes da maioria das disciplinas. Associam o aprender EF com um corpo que se restringe apenas ao movimento, pensado de maneira anátomo-fisiológica; e quando a aula se desenvolve no espaço fechado da sala, no qual são obrigados a se manter em suas carteiras, entendem como uma prática não natural à disciplina, como destaca Karen: "podendo jogar um vôlei, eu vou ficar dentro da sala escrevendo? Nem parece EF”.

Além desses estranhamentos, surgem outras problemáticas que interferem diretamente no interesse do aluno em aprender. As maiores queixas estão relacionadas à repetição de conteúdos que, em sua maioria, se resumem ao ensino de quatro modalidades esportivas (vôlei, basquete, futebol e handebol).

Observamos, ainda, com base no estudo de Vieira et al. (2012), que a não diversificação de conteúdo associada a sua repetição nos diferentes anos de escolarização, sem um aumento de sua complexidade, tem provocado um desinteresse do aluno pelas aulas de EF, sobretudo nos momentos de transição dos níveis de ensino, como do Ensino Fundamental I para o Ensino 
Fundamental II e, assumindo outra característica, com a entrada do jovem no Ensino Médio, como veremos mais adiante no texto.

Um ponto que se destacou nas narrativas de Carla e de Fernanda em relação aos interesses dos estudantes nas aulas é que essas se diferenciam não somente com o espaço onde acontecem, mas também em virtude de experiências consideradas por elas negativas. O que se percebe é um desinteresse nas aulas fora da sala, onde há uma maior exigência de elaborações corporais por parte dos alunos, que ora não tiveram boas experiências em virtude das críticas vindas, declarada ou veladamente, de colegas e professores, sofridas pela falta de habilidade com as práticas esportivas.

Porque é trágico você tentar jogar e não conseguir, porque eu não levava jeito mesmo. Aí é só crítica em cima de mim. (Carla)

Por que o que acontece na quadra? O professor senta lá, coloca alguém para ser o juiz. Seus colegas que vão mais te ensinando, sendo que aluno nem sabe nada direito, um aluno ensinando o outro, por isso que eu nem gosto. Na quadra, eu só aprendi a chorar, perder, ser zoada, cair e levantar de novo. (Fernanda)

$\mathrm{Na}$ visão das alunas, a dificuldade motora ao realizar determinada atividade acabava expondo-as perante a turma, ficando como foco de críticas e brincadeiras que geram uma exclusão e rejeição por parte dos colegas, sobretudo daqueles que possuem mais habilidade. Destacam, ainda, que essas práticas são quase sempre ignoradas pelo professor, que não intervém ou, às vezes, acaba por corroborar os processos de exclusão, como demonstra a narrativa de Bianca:

Eu sei que aprendi quando não sou mais alvo da "zuação"! Quando o professor passa uma atividade, por exemplo aprender a sacar no vôlei, sempre têm aqueles que se destacam mais e quem não se destaca vira motivo de piada. Então, quando eu deixo de ser motivo de piada e o outro colega que sabe menos que eu é que fica sendo "zuado" em vez de mim, então eu sei que aprendi. (Bianca)

O diálogo com a narrativa nos faz pensar que existem questões motoras e também de gênero presentes nessa perda de interesse indicada. Devido à especificidade dos saberes com os quais a EF trabalha, ligados principalmente ao domínio de atividades corporais, as práticas desenvolvidas tornam evidentes o maior ou menor capital motor do aluno. 


\section{pro.posıções}

$e$-ISSN 1980-6248

http://dx.doi.org/10.1590/1980-6248-2019-0074

As meninas, por exemplo, perdem o interesse nas aulas, sobretudo na transição do Ensino Fundamental I para o Fundamental II. Daniela destaca em seu cartaz, exposto na figura 1, que acha a aula chata "porque eu odeio qualquer tipo de esporte. Tipo... Esportes me machucam... Aí quebra unhas...".

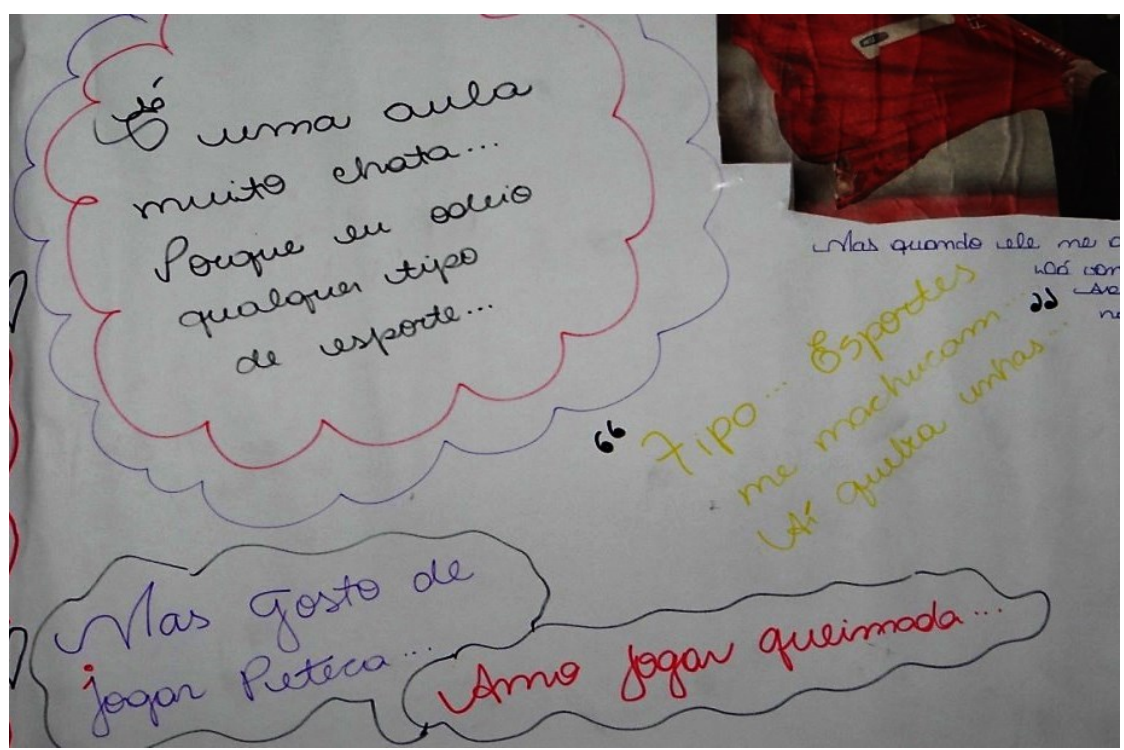

Figura 1 - Cartaz de Daniela

\section{Legenda:}

É uma aula muito chata...

Porque eu odeio qualquer tipo de esporte...

"tipo... Esportes me machucam...

Aí quebra unhas..."

Mas gosto de jogar peteca...

Amo jogar queimada...

Dialogando com o cartaz de Daniela, percebemos essa rejeição das alunas ao conteúdo esportivo. O desinteresse possivelmente ocorre por haver um deslocamento delas em relação ao que se quer, ao que as motiva. Vejamos, a própria aluna Daniela afirma que odeia esporte, "mas gosto de jogar peteca... Amo jogar queimada". Não é uma rejeição a todas as atividades que exigem movimento e habilidade, portanto não se refere apenas às práticas motoras da $\mathrm{EF}$ de uma forma geral, mas a uma rejeição ao conteúdo esportivo especificamente. Essa exigência da técnica esportiva e das habilidades também pode acabar por fazer comparações entre as meninas e os meninos (Duarte \& Mourão, 2007).

Percebe-se também, no cartaz, uma questão presente: como o cuidado maior com o corpo e com a aparência que as meninas começam a desenvolver com a entrada na puberdade 


\section{pro.posıções}

$e$-ISSN 1980-6248

http://dx.doi.org/10.1590/1980-6248-2019-0074

interfere diretamente nas suas preferências e interesses na disciplina? "Tipo... Esportes me machucam... Aí quebra unhas" (Daniela).

Esse tipo de apontamento demonstra que o fator gênero e as diferentes fases vividas pelos grupos de alunos e alunas também influenciam seus discursos, seu modo de agir, de pensar, de significar e, consequentemente, ressignificar os conteúdos que perpassam de maneira direta pelas práticas, de/para um corpo-sujeito que a todo momento está em constante transformação.

No diálogo com uma pesquisa desenvolvida em escolas de ensino fundamental da Espanha (Gil-Madrona, Cachón-Zagalaz, Diaz-Suarez, Valdivia-Moral, \& Zagalaz-Sánchez, 2014), identificamos, em outro movimento analítico, que as diferenças na hora de escolhas de atividade física pelos jovens perpassam por aquilo que trazem do vivido/praticado fora da escola, em diferentes ambientes, como sua casa, rua, praças, academias, e muitas vezes se deseja que essas práticas sejam incorporadas na escola.

É nesse sentido, do não diálogo com aquilo que os alunos vivenciam fora da escola, que a figura 2 sinaliza uma EF que deixa de compreender as necessidades dos estudantes.

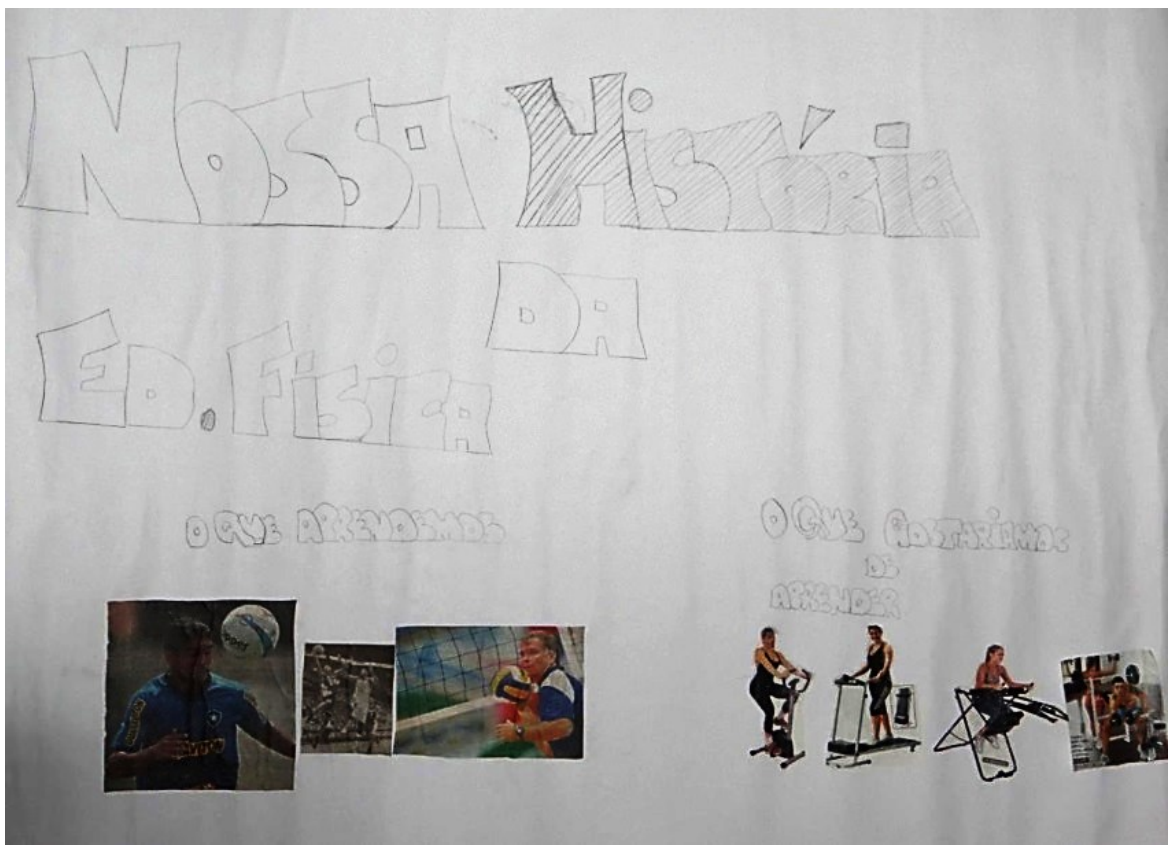

Figura 2 - Cartaz de Karen e Paulo

\section{Legenda:}

Nossa história da Ed. Física

O que aprendemos

O que gostaríamos de aprender 


\section{pro.posıções}

$e$-ISSN 1980-6248

http://dx.doi.org/10.1590/1980-6248-2019-0074

Os alunos Karen e Paulo, ao elaborarem o cartaz sobre a EF em sua vida escolar, sintetizaram a história deles com o aprendizado de determinados conteúdos, porém desejando aprender outros. Parece haver uma necessidade de os alunos terem seus conhecimentos ampliados, e não somente resumidos ao aprendizado dos esportes.

As narrativas sinalizam como é mais fácil ou mais difícil aprender algo em EF de acordo com as vivências com a disciplina, associando preferências pessoais, prática pedagógica e metodologia de ensino. Assim, nota-se uma crítica, por parte dos alunos, de que a escola não ensina algo novo, e quando esse "novo" é apresentado, às vezes com uma metodologia diferenciada, o aluno acaba desenvolvendo um interesse pelo conteúdo e se coloca aberto à experiência, conforme expõe Fernanda em seu relato:

A aula teórica dela foi toda em vídeo, ela não chegou a escrever. Foi melhor, você vendo chama mais atenção, e depois ir lá ver como acontece na prática, você quer ficar ali vendo tudo que eles fazem, a gente aprende mais assim, motivado! E teve aula na piscina também. Eu não sei nadar, mas a professora insistiu que eu tinha que ir, estava lá quase me afogando, mas ela estava perto ajudando e foi muito divertido. É muito melhor aula prática fora da sala porque a gente aprende mais! Quer dizer, depende da aula prática, na quadra eu não gosto. Por que o que acontece na quadra? O professor senta lá, coloca alguém para ser o juiz. Seus colegas que vão mais te ensinando .... Na sala eu via muito filme também, que sempre tem uma lição de moral, filmes sobre jogos, mas o professor não ensinava só sobre a parte do jogo, ensinava que a EF envolve você todinho, ensinava persistência, que você nunca pode desistir. Essas coisas, os professores de EF trabalhavam muito nessa área também das coisas de sentir. (Fernanda)

A narrativa da Fernanda oferece elementos para pensarmos a maneira como a prática pedagógica docente motiva os alunos e aumenta o interesse na aula, fazendo com que eles estejam dispostos a aprender aquilo que se apresenta como "novo". No entanto, é preciso compreender qual sentido se atribui ao "novo" e como isso se dá.

O "novo" pode ser a existência de um conteúdo que ainda não foi ensinado. "teve uma vez que a professora falou de esporte adaptado, e fomos visitar o pessoal que jogava basquete e eram cadeirantes. ... nós fomos lá ver eles, não foi só basquete, foram vários jogos, até futebol ... Foi muito legal!" (Fernanda).

O "novo" pode ser interpretado como aumento de complexidade daquilo que foi e/ou está sendo ensinado. "A EF é muito importante porque, sem ela, eu não teria o desenvolvimento que eu tenho hoje, de saber correr, saber nadar, saber jogar bola" (Rafaela). 


\section{pro.posıções}

$e$-ISSN 1980-6248

http://dx.doi.org/10.1590/1980-6248-2019-0074

O "novo" também se apresenta na diferenciação daquilo que se aprende na rua. "As coisas da EF eu aprendi mais na rua, jogando com os colegas e meus irmãos. Então não exige tanto esforço para entender" (Paulo).

É importante compreender que, algumas vezes, os elementos que apresentam e anunciam esse "novo" produzem desmotivação e/ou motivação para a aula de EF. Essa não é uma questão atual, Dewey (1978) já ressaltava que o processo educacional nada mais é do que o processo de viver. Nesse sentido, é fundamental perceber primeiro o(s) interesse(s) e a(s) motivação(ões) de cada aluno, que são, na sua essência, pessoais e emocionais, "resultado que acompanha a identificação do 'eu' com um objeto ou ideia”' (p. 70), e depois o esforço, que pode persistir junto ao interesse ou se opor a ele. Para o autor, "ensinar bem é ensinar apelando para as capacidades que o aluno já possui, dando-lhe, do mesmo passo, tanto material novo quanto seja necessário para que ele reconstrua aquelas capacidades em nova direção, reconstrução que exige pensamento, isto é, esforço inteligente" (p. 93).

A ação docente se apresenta como um fator na facilitação ou dificuldade dos aprendizados, assim como foi apontado pelas narrativas a respeito da articulação entre teoria e prática e como isso se organiza na concepção dos alunos. "Na prática você aprende muito mais. Não aprende a questão da habilidade, mas, pelo menos, o que fazer você sabe [...] só não sabe fazer certo, mas sabe pelo menos a teoria, porque na prática também aprende teoria” (Karen).

No caso analisado, essa articulação entre teoria e prática na atuação do professor de EF foi a forma que mais facilitou o aprendizado dos alunos, como foi apontada na narrativa de Karen.

Um dos problemas mais evidenciados em relação ao aprendizado foi a falta de orientação do professor; nas narrativas de Leandro, Laís e Catarina, a própria presença dele na aula já é tida como um diferencial, como algo que não fosse comum nas aulas.

Para aprender, tem que ter a presença do professor. (Leandro)

É difícil aprender quando o professor não sabe de nada. Que nem da $1^{\mathrm{a}}$ à $4^{\mathrm{a}}$, o professor só deixava a gente fazer o que quisesse, nem parecia que era formado, nem dava aula. Como ia aprender? (Laís)

É difícil aprender com o professor que não pega no pé do aluno, que nem falamos lá na sala "tem professor que só dá a bola e deixa o aluno fazer". Porque eu acho que só aprende com o 
professor que vai lá ensina teoria, diz como é que é as regras, e depois vai para a prática. É assim que eu aprendo, tem que ensinar e estar presente. (Catarina)

As narrativas sinalizam para a construção da identidade de um professor de EF "descomprometido" com a prática pedagógica, mas para compreender por que se constrói esse tipo de imagem, analisamos as narrativas dos estudantes que destacam as características atribuídas por eles ao professor.

É bom o professor estar na quadra, presente. É bom estar na quadra ajudando. Se tem muita dificuldade, ele diz "não, tem que fazer assim". Se, por exemplo, ele vê que o aluno dele está indo mal no saque, se necessário ele vai pegar até na mão do aluno para ensinar a sacar. Agora, se ele não está vendo, como ele vai ajudar? A maioria dos meus professores nem ficavam na aula, dava a bola, saía e ia tomar um chazinho. Nem sabia o que você aprendia, até por que nem tinha como aprender, né?, sem o professor. E quando estava, era a mesma coisa de não estar, só deixava os meninos jogarem. (Bianca)

O bom professor é o que está presente, ensinando a fazer as coisas certas, sem mandar demais também, tem que deixar o aluno livre ... Na EF, o professor é mais legal, a gente faz o que quiser. Mesmo que ele seja um professor ruim, não dê aula de verdade, geralmente é mais de boa, a gente pode conversar de igual para igual com ele. (Karen)

Apesar de trazer algumas narrativas como experiências positivas, os alunos não as associam com as práticas pedagógicas dos professores. A identidade que prevalece na análise dos estudantes privilegia a denúncia e se pauta numa perspectiva negativa, focalizando o discurso na falta e silenciamento das práticas que se constituíram em experiências significativas de aprendizado.

Esse não é um problema específico deste trabalho. Falcão, Ventorim, Santos e Ferreira Neto (2012), ao abordar a avaliação que os alunos participantes de um projeto pedagógico fazem do processo, enfatizam como esta assume um caráter negativo, pautando-se nos problemas, nas ausências e nas dificuldades.

Como foi apresentado antes, o aluno frequentemente atribui sentido positivo e sente anseio por aquilo que entende como novos conteúdos, aulas diferentes e mais interessantes, entretanto a maneira como é realizada a interferência pedagógica não tem boa receptividade, $\mathrm{e}$ se o professor não interfere, também é visto como um docente descomprometido. "A gente reclama que o professor não dá aula, mas reclamamos também de que se ele interferir, a aula fica chata. Eu nem sei mais o que eu quero do professor!” (Helson). 


\section{pro.posıções}

$e$-ISSN 1980-6248

http://dx.doi.org/10.1590/1980-6248-2019-0074

Uma análise a ser feita é que essa resistência à interferência do professor vem da sensação de liberdade supracitada, de poder tomar as atitudes e conduzir o que vai acontecer. Porém, esse sentido de liberdade nas aulas, na qual o aluno diz poder fazer o que quiser dela, denotaria a não identificação de uma estratégia do professor em permitir que isso ocorra de maneira planejada.

Outra análise desse tipo de narrativa leva-nos a refletir sobre questões de fundo que remetem à identidade da EF, ao que ela ensina, ao seu papel na escola e às expectativas que cada aluno cria em relação a essa aula de acordo com suas representações em cada etapa de ensino. É preciso evidenciar que os alunos também não entram em acordo em relação a que expectativa é essa que deve ser atendida, uns dizem que a aula deve trazer o "novo", porém assumem narrativas de que deve ser livre, pois é preciso ter o lazer, o "recreio". "Sinto muito, mas a escola é cadeia. A EF deixa a gente livre um pouco, a gente pode conversar, rir, ficar na sua quieto se quiser, sem ter um professor fazendo 'cala a boca"' (Karen).

Por sua vez, eles querem uma presença mais firme do professor, que apresente algo novo e amplie seus conhecimentos sobre aquilo que está sendo ensinado, como os outros professores. "É bom o professor estar na quadra, presente. É bom estar na quadra ajudando. Se tem muita dificuldade ele diz 'não, tem que fazer assim”' (Bianca). Mas não aceitam tudo que é proposto, "o bom professor é o que está presente, ensinando a fazer as coisas certas, sem mandar demais também, tem que deixar o aluno livre" (Karen). Assim, ficamos com a frase de Helson, quando diz: "Eu nem sei mais o que eu quero do professor!”.

A autonomia e o lugar de protagonismo dado ao aluno é uma questão que sempre emerge das narrativas, pois eles os reconhecem como características específicas no compartilhamento e apropriação dos saberes da EF. Porém, aliados à dificuldade que os estudantes apontam em identificar os saberes da disciplina como aprendizados, essa autonomia e protagonismo fazem a EF ser confundida como matéria em que não há orientação, como horário livre, como algo que "na prática é só bobeira" (Karen) ou "o lazer da escola" (Helson).

Poderíamos inferir que, relativamente, foram poucas as narrativas que destacaram aulas de EF organizadas, estruturadas, diferenciadas em sua prática pedagógica, porém é preciso entender que os alunos opinam e dizem o que querem do outro constantemente. Isso sinaliza a necessidade de analisar qual é a reponsabilidade do aluno no seu processo de aprendizado. A crítica ao professor também é válida, mas é preciso ser feita uma autocrítica por parte do aluno, 


\section{pro.posıções}

$e$-ISSN 1980-6248

http://dx.doi.org/10.1590/1980-6248-2019-0074

no sentido de perceber e problematizar em que medida de fato, por exemplo, ele quer participar de determinada aula. Essa "visão negativa" é uma característica que transcende a todo momento suas ações.

Assim, nas tensões identitárias entre o que se quer do professor e o que é ensinado, Neira e Nunes (2009) sinalizam que esse embate pode ser negociado, na construção do planejado da EF, na superação de ensino de práticas corporais completamente afastadas do universo cultural dos alunos que estão no mundo que forma e informa. O professor pode discursar sobre a importância da participação coletiva, do respeito aos tempos de aprendizagem de cada um e garantir que todos peguem na bola, dancem ou brinquem. Além disso, levar os discentes a dialogar sobre sua gestualidade, analisar sua história, descobrir quem são e como pensam seus jogadores e técnicos profissionais e tantas outras marcas presentes em qualquer prática corporal também é importante (Neira \& Nunes, 2009).

Apesar de não terem $\mathrm{EF}$ no $3^{\circ}$ ano, os alunos salientam que gostariam de ter $\mathrm{o}$ componente curricular de volta, no entanto o que se apresenta não é o desejo pela aula, mas sim pelo momento da EF para não ter aula, para fugir daquilo que consideram sufocante, restritivo, que é a lógica das demais matérias escolares.

Levando em consideração as narrativas sobre o histórico de escolarização, em que o aluno entende não poder fazer o que quer nas outras disciplinas, por que se constrói ao longo da escolarização uma identidade para a EF cuja característica é a permissão de qualquer atitude, inclusive a de não fazer aula? Compreendemos que essas identidades não se constroem apenas em discursos, são ancoradas também nas práticas do corpo-sujeito.

Sinto muito, mas a escola é cadeia. A EF deixa a gente livre um pouco, a gente pode conversar, rir, ficar na sua quieto, se quiser, sem ter um professor fazendo "cala a boca". Na aula de EF, se quero jogar vôlei? Jogo! Cansei? Quero dançar? Danço, cansei?! Vou voar, faço o que eu quiser! (Karen)

É uma aula mais livre, porque a gente sai da sala, porque a gente faz o que a gente gosta, senta, conversa. Na maioria das matérias, a gente só vê, na maioria das vezes, coisas que a gente não gosta. (Bianca)

A EF é o lazer da escola. Sair da sala uma hora por semana, meu Deus, pelo menos um banho de sol a gente tem que ter, né? A gente quer dizer que a EF é um momento de descontrair, não ficava aquilo de matéria, teoria, a gente podia sair um pouco, conversar um pouco, praticar um esporte. (Helson) 


\section{pro.posições}

$e$-ISSN 1980-6248

http://dx.doi.org/10.1590/1980-6248-2019-0074

Quando analisamos os cartazes feitos pelos estudantes, nos quais eles criaram livremente composições sobre a EF, também pudemos perceber as identidades atribuídas à disciplina que a caracterizaram como espaço plural. Identificamos essa questão no cartaz de Catarina e Helson, figuras 3 e 4 respectivamente.

Figura 3 - Cartaz de Catarina

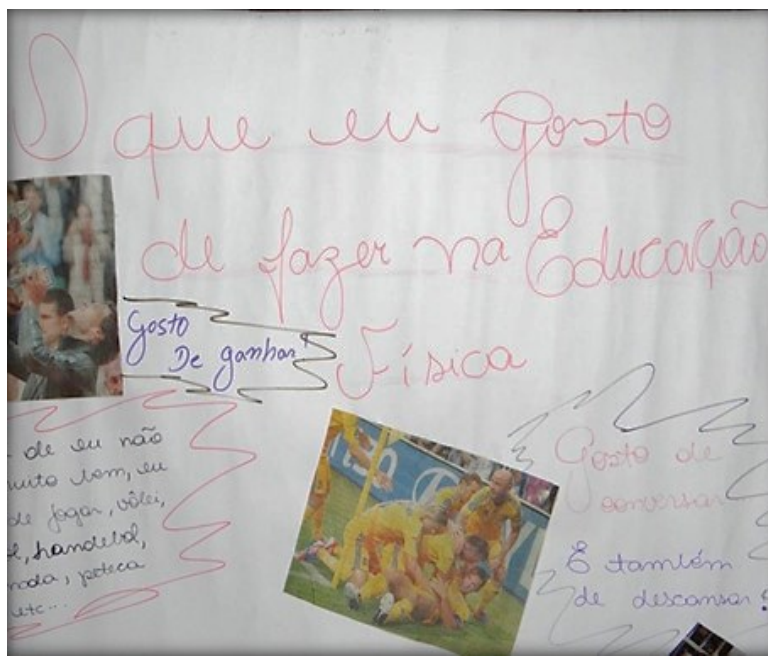

Legenda:

O que eu gosto de fazer na Educação Física

Gosto de ganhar

Gosto de conversar

E também de descansar!
Figura 4 - Cartaz de Helson

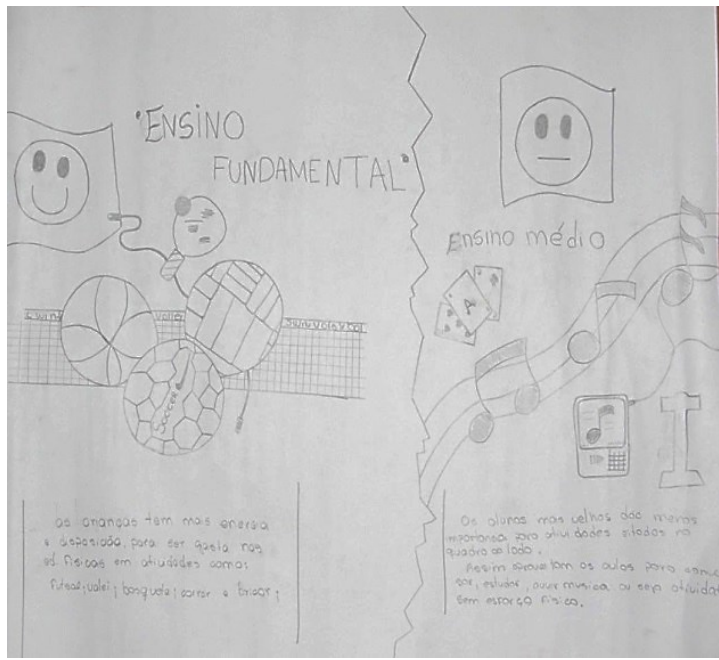

Legenda:

Ensino Fundamental

...as crianças tem mais energia e disposição para ser gasta na ed. física em atividades como: futsal; vôlei; basquete; correr e brincar.

Ensino médio

Os alunos mais velhos dão menos importância para atividades citadas no quadro ao lado.

Assim aproveitam as aulas para conversar, estudar, ouvir música, ou seja, atividade sem esforço físico.

Percebemos na Figura 3 que a estudante atribuiu como algo que lhe agrada na EF o fato de poder "ganhar, conversar e descansar", ressaltando a construção da identidade de uma disciplina em que se tem a liberdade para fazer atividades cujos saberes relacionais se sobressaem, como socializar com os colegas e até mesmo ganhar, semelhante aos horários vagos da escola.

O cartaz do Helson, na Figura 4, demonstra como a EF tem significados diferentes no Ensino Fundamental e no Ensino Médio. Observamos que Helson atribuiu à EF no Ensino Fundamental diversos aprendizados. Identificamos facilmente as bolas de basquete, futebol e 


\section{pro.posıções}

$e$-ISSN 1980-6248

http://dx.doi.org/10.1590/1980-6248-2019-0074

vôlei, a rede também de voleibol, uma raquete de tênis de mesa e uma representação de como se sente o estudante no Ensino Fundamental durante as aulas, com um sorriso no rosto, seguido por uma narrativa escrita que diz "As crianças tem mais energia e disposição para ser gasta na Ed. Física, em atividades como: futebol; vôlei; basquete; correr e brincar”. Aqui os saberes práticos (saber de domínio) são tidos como centrais nas significações acerca da EF nessa etapa de ensino.

Em contrapartida, o estudante atribui à EF no Ensino Médio diversas imagens características de momentos de lazer, como o baralho, celular com fones de ouvido e música, além da representação de como se sente nas aulas nesse período: um boneco sem o sorriso anterior, seguido pela narrativa escrita que diz "Os alunos mais velhos dão menos importância para as atividades citadas no quadro ao lado. Assim aproveitam as aulas para conversar, estudar, ouvir música, ou seja, atividade sem esforço físico".

Como na Figura 3, a Figura 4 evidencia os saberes-relacionais como elementos importantes associados à EF no Ensino Médio, principalmente no $3^{\circ}$ ano, quando não se tem esse tipo de aula na maioria das vezes. Mas, afinal, essa é mesmo uma crítica à EF ou à escola e sua lógica de escolarização? Questão essa que trataremos a seguir no próximo eixo.

\section{O que o aluno aprende e que faz com o que aprende na EF?}

Analisando as pistas (Ginzburg, 1989) deixadas durante o percurso narrativo, identificamos o aprender na EF na perspectiva dos alunos e buscamos entender as identidades construídas na comparação com a lógica de ensino das outras matérias feitas pelos estudantes, partindo da relação com os saberes das disciplinas.

No diálogo com Hall (2000), percebemos que o conceito de identidade, como algo acabado e próprio de determinados grupos e/ou áreas, com seus códigos e símbolos traduzidos por tradições que valorizam um tipo de saber em detrimento de outras formas de aprender e ensinar, acaba por institucionalizar um ideário de escola que "padroniza", por meio de discursos de igualdade, a definição do que é importante e o que não é para determinada lógica estipulada. Porém, é necessário frisar que a leitura realizada da EF deve levar em consideração que ela assume a perspectiva das práticas como referência. Nesse sentido, concordamos com Hall ao concebermos que as identidades: 
não são nunca unificadas; que elas são, na modernidade tardia, cada vez mais fragmentadas e fraturadas; que não são, nunca, singulares, mas multiplicamente construídas ao longo de discursos, práticas e posições que podem se cruzar ou ser antagônicas. As identidades estão sujeitas a uma historização radical, estando constantemente em processo de mudança e transformação. (p. 108)

Nessa visão, entende-se que não podemos assumir uma ideia fixa, central e permanente de identidade, principalmente para a escola, lugar plural que demarca o "encontro" dos diferentes saberes e atores. Entretanto, apesar de não se ter uma identidade única para o que conhecemos por escola, percebe-se determinada insistência em se manter uma tradição cultural que a demarca e que busca manter seus pilares. Dessa forma, a escola, concebida como o lugar da palavra, da escrita e de demais formas de simbolização do mundo, tende a valorizar as disciplinas que têm em seu estatuto epistemológico, sobretudo, a apropriação de saberes-objeto, uma vez que essa identidade "tradicional" se construiu ao longo do tempo como a identidade escolar mais adequada, que constitui a lógica de ensino.

Do ponto de vista escolar, a Educação Física desempenha a mesma função das outras disciplinas, no entanto estabelece outra racionalidade. Pode-se dizer que ela é dúbia, visto que, ao mesmo tempo que assume uma lógica, também se distancia dela, para depois se reaproximar com as ressignificações, em um movimento de prática-teoria-prática que não deve ser analisado de maneira fragmentada. A EF se apropria da tradição para se manter como componente curricular, mas também confere outros sentidos aos conteúdos, em um movimento de tradução por meio das diferenciações que ela estabelece.

Dewey (1978) aponta que "sempre que a atividade física tiver de ser aprendida deve apresentar um valor intelectual” (p. 98). Para ele, existem cinco condições para aprender: (i) só se aprende o que se pratica; (ii) mas não basta praticar; (iii) aprende-se por associação; (iv) não se aprende nunca uma coisa só; e (v) toda aprendizagem deve ser integrada à vida. Nesse sentido, as práticas estão relacionadas às experiências (intelectuais, sensoriais, motoras e sociais) adquiridas pelo corpo-sujeito que "vive" a escola e nela estabelece diferentes relações com os saberes e a própria maneira de lidar com a vida, ao longo do seu desenvolvimento durante as fases da escolarização.

Para compreender como se estabelece essa relação de comparação entre o que são e como são aprendidos os saberes nas aulas de EF e nas outras matérias, evidenciamos o que os jovens narram a respeito. 
A diferença da EF com as outras matérias é que é mais prática do que escrita. Dizer o que aprende em EF é muito difícil do que dizer o que aprendi em matemática. Porque na prática é só bobeira, essa é a verdade. Bobeira porque, querendo ou não, jogar uma bola ali não é mais importante do que aprender uma parada de matemática que posso usar para o meu futuro profissional. Eu acho necessário? É necessário, mas menos importante! (Karen)

Porque matemática e português é essencial na nossa vida para se comunicar, no trabalho. Já a EF não é tão importante; assim, é importante, mas não é necessário, sei lá! Porque matemática, português tem uma necessidade maior talvez em questão de carreira profissional, se comunicar com as pessoas, e a EF não vai ter tanta influência nesse aspecto. E também outra diferença é que na EF você não esquece, porque é prático, a gente já vai fazendo e gravando aquilo para a vida. Na matemática não, é fórmulas e fórmulas e você vai sempre precisar recorrer ao caderno. (Helson)

Eu não gosto de EF, para mim é igual matemática. Eu também não gosto, mas matemática eu pelo menos vou usar na minha vida para arranjar um emprego. Sei lá, então é mais importante, eu tenho que aprender. (Daniela)

O que se destaca nas narrativas dos alunos é um sentido do aprender voltado para a lógica que é valorizada pela escola, em que a apropriação de saberes de domínio é menos importante, numa relação de comparação com a forma como se aprende nas outras matérias, em que os saberes-objeto são representados como aqueles importantes de fato.

Aqui fica claro o momento da vida em que esses jovens estão, um momento de decisões e dilemas. Carla, por exemplo, afirma que não aprendeu nada, mas "na sala a professora passava basicamente as regras do vôlei. Pelo menos isso eu aprendi ... e fora da sala ... tirando a dança, eu não aprendi nada". Ela diz não ter aprendido nada, todavia aprendeu a dança "pelo menos", o que nos evidencia a necessidade de nos questionarmos: não aprendeu em relação a que?

O Ensino Médio é permeado por essas tensões, em que a profissão, a entrada no mercado de trabalho, a futura faculdade, o Exame Nacional do Ensino Médio (Enem) e o futuro de maneira geral estão latentes a todo momento no cotidiano dos jovens. Isso pode ser um indício dessa visão mais “negativa” em relação à EF no final do ciclo da Educação Básica. Dewey (1978) já nos alertava que a educação precisa ser compreendida como esse processo de construção, reconstrução e reorganização das experiências e que tal exercício nos faz perceber cada vez mais as experiências futuras de uma maneira melhor. "Por essa definição a educação é fenômeno direto da vida, tão inelutável como a própria vida" (p. 17).

Para Carrano (2003), a maneira como os jovens organizam territórios, identidades e culturas próprias, muitas vezes não toleradas pelos outros, principalmente os adultos, acaba por gerar tensões no cotidiano escolar. Nesse sentido é importante compreender que 
a escola pode ser considerada como integrante da cidade em ruínas, onde se experimenta conflitos, não necessariamente violências, que causam ruídos na comunicação. Nesse sentido, se faz necessário a abertura por práticas coletivas juvenis que penetram em seus tempos e espaços administrativo-pedagógicos. De espaço orientado para a uniformização e o anonimato (jovens como alunos), a escola pode ser um novo território onde as identidades juvenis encontrarão espaço para o diálogo. (p. 47)

As análises não devem centrar-se apenas na existência ou não do componente curricular EF na escola, é preciso levar em consideração que existe uma dicotomia entre a lógica escolar e seu funcionamento e o modo como essa disciplina deve ser ministrada, reconhecendo o interesse dos jovens, as diferentes identidades criadas por eles e o papel social que desenvolve na escolarização.

Quando falamos de lógica escolar, no diálogo com Hérbrad (1990), remetemo-nos à escola como um lugar onde as práticas culturais são internalizadas por meio de diferentes sistemas simbólicos, materializados em dispositivos que instruem e instituem a leitura e a escrita como aprendizagens anteriores a todas as disciplinas.

A escola tem na sua centralidade o lugar da palavra, da escrita e de formas de simbolização do mundo, do texto, dos saberes sistematizados, cujo modo de existência é a linguagem; a EF valoriza a relação do "corpo-sujeito com o mundo, um mundo compartilhado com outros, uma forma incorporada de ser dono de si mesmo e do seu ambiente" (Charlot, 2009, p. 246), pelas diferentes vias das práticas. Desse modo, compreender a lógica de organização da escola, em que há valorização das disciplinas cujos dispositivos de registro instrumentalizam o ensino aos alunos para aprová-los no vestibular, inseri-los em uma escola técnica e/ou prepará-los para o campo do trabalho, ajuda-nos a perceber melhor o modo como esse jovem olha para seu processo de escolarização.

Essas são questões de cunho amplo, de escolarização como um todo, porém, também existem aquelas que são pertinentes à prática pedagógica do professor. Assim, essa ação pedagógica do professor tem que buscar ampliar a constituição das práticas que estabelecem o patrimônio material e cultural da humanidade (no jogo, na dança, no esporte). Paulo, por exemplo, destaca que "as coisas da EF eu aprendi mais na rua, jogando com os colegas e meus irmãos. Então não exige tanto esforço para entender quanto as outras matérias tipo matemática e português que eu nunca vi as coisas que têm lá”. 


\section{pro.posıções}

$e$-ISSN 1980-6248

http://dx.doi.org/10.1590/1980-6248-2019-0074

Nesse caso, por exemplo, é preciso compreender que a EF não pode se limitar a trabalhar os conteúdos apenas vistos pelos alunos na rua. O início da abordagem até pode ser por esse caminho, mas a partir daí é necessário ampliar os conhecimentos desse jovem, pois afinal: o que o aluno aprende na aula de EF? É partindo da identificação do que ele aprende que é possível também captar o que ele faz com o que ele aprende.

É preciso ponderar que existe uma distinção quando se analisa essa questão olhando as práticas dos alunos. As narrativas abaixo já estabelecem outro olhar para os conteúdos da EF, na medida em que sinalizam que as experiências vivenciadas nela e por ela contribuíram para o aprendizado de determinadas práticas corporais.

A EF é muito importante porque, sem ela, eu não teria o desenvolvimento que eu tenho hoje, de saber correr, saber nadar, saber jogar bola; não ia saber chegar no meio das pessoas e praticar aquilo. Como eu ia saber essas coisas? Fora da escola eu jamais ia aprender isso. (Rafaela)

Só o fato de já ter aprendido como jogar, já ter aprendido a fazer alguma atividade já é alguma coisa. Mesmo que eu não tenha oportunidade de jogar e de usar isso. Se não fosse aqui para aprender, onde eu ia aprender essas coisas? Então já valeu pelo aprendizado. (Bianca)

As narrativas de Rafaela e Bianca indicam a probabilidade de elas não terem tido contato com os conteúdos da EF fora da escola e por isso atribuem uma maior importância aos saberes compartilhados, diferentemente de Paulo.

Schneider e Bueno (2005) acenam para a possibilidade de a escola ser um dos poucos espaços nos quais as meninas têm acesso a determinados elementos das práticas corporais como, por exemplo, os esportes. As narrativas da Rafaela e da Bianca reforçam essa possibilidade, porém carecem ainda de um estudo aprofundado para compreendermos como os acessos às práticas corporais fora da escola interferem no interesse e na importância que os estudantes dão à EF e como questões de gênero têm atravessado a temática na atualidade.

Percebe-se que a diferença nas narrativas nos apontam ser esse não só um problema do projeto de escolarização. Por isso é preciso compreender também em que medida a EF está constituindo um arcabouço que faz o aluno ampliar a apropriação das práticas corporais ou o que temos chamado de práticas constituintes do nosso patrimônio cultural e material, para além do que se aprende na rua, e em que medida a identidade da EF perpassa por transformações nas representações desses jovens ao longo da escolarização. Nesse ponto temos que nos atentar 
para questões importantes, que são: "Eu gosto de EF? Mas o que eu vou aproveitar da EF na vida? O que eu farei com o que aprendi?” Karen e Catarina deixam claro que

é importante só porque eu aprendi o vôlei, que eu usei bastante. Então foi importante porque eu fiz alguma coisa fora daqui. Mas se for pensar no profissional, a EF não é tão importante se, por exemplo, eu quiser fazer uma engenharia, muito mais importante aprender matemática. (Karen)

Estamos aqui na escola, eu penso que é para ralar, estudar bastante e no final da vida escolar fazer a prova, passar na faculdade ... Em EF tem o professor que fica à toa e o aluno só praticando esporte, mas tem professor que gosta de explicar, falar as regras e ensinar a praticar e eu garanto que, por causa desses, tem um monte de gente aqui que quer ser professor de EF. Então, para eles a disciplina foi importante, mas para mim não foi. (Catarina)

Como dito, as preocupações dos jovens no Ensino Médio estão muito ligadas à inserção no mercado de trabalho, a uma carreira, a construir a si mesmo como ser humano no mundo adulto e se fazer reconhecer como tal. Portanto, a importância do que se aprende na EF está diretamente relacionada ao momento da vida que estão atravessando, pois é a partir desse ponto que atribuem mais ou menos significado aos saberes compartilhados na disciplina, independentemente dos objetivos dela (Backes, 2018).

Apesar de os alunos, em algumas narrativas do outro tópico e também em narrativas desse próprio eixo, sinalizarem que não aprenderam nada ou que o que se aprende não tem relevância, foi preciso captar, nas pistas deixadas, que eles ressaltaram a aprendizagem:

na sala, a professora passava basicamente as regras do vôlei, pelo menos isso eu aprendi. (Carla)

Sem ela, eu não teria o desenvolvimento que eu tenho hoje, de saber correr, saber nadar, saber jogar bola. (Rafaela)

As crianças tem mais energia para ser gasta na Ed. Física em atividades como: futsal; vôlei; basquete; correr e brincar. (Helson)

Inclusive, Bianca e Karen vão salientar a relação desse aprendizado com a vida, com as práticas fora da escola, ao afirmarem: "é importante só porque eu aprendi o vôlei, que eu usei bastante. Então foi importante porque eu fiz alguma coisa fora daqui”" (Karen). "Só o fato de já ter aprendido como jogar, já ter aprendido a fazer alguma atividade já é alguma coisa" (Bianca).

A educação para a vida, tão discutida por John Dewey, é algo que transcende a "mecanização" do processo de escolarização e o "enquadramento" do indivíduo em padrões pré-estabelecidos e conhecimentos tidos como muito e/ou pouco importantes, pois temos de entender que eles são para o mundo, para as relações e para a vida como um todo. 


\section{pro.posıções}

$e$-ISSN 1980-6248

http://dx.doi.org/10.1590/1980-6248-2019-0074

Por fim, é preciso considerar que estamos lidando com jovens que estão olhando para trás perspectivando a sua trajetória de aprendizado com a EF na escolarização, porém esse jovem tem traçado para ele, no presente, um futuro que significa a entrada no mercado de trabalho e o vestibular, questões recorrentes em suas falas.

Assim, é frequente uma contraposição que se faz entre a EF, a matemática e a língua portuguesa, colocando como questão central o que e como essas disciplinas podem contribuir para a profissionalização.

Dessa maneira, não é possível fixar um conceito acabado de identidade que o jovem vai atribuindo à EF durante a escolarização, uma vez que ele vai se modificando, moldando-se de acordo com seus interesses e suas fases. Ao mesmo tempo também não é possível fixar um conceito único de juventude, pois os jovens vão se transformando, constituindo projetos de vida e de formação que se diferenciam e interferem na compreensão sobre a identidade da vida, da escola e própria EF, sobre o que ela ensina, o que se aprende e o que se faz com o que se aprende nesse componente curricular. Nesse sentido, a produção de sentidos deve ser "medida" de maneira ampla e levando em consideração uma série de fatores e atores que fazem parte do processo.

\section{Considerações finais}

Neste artigo, compreendemos as relações que os alunos do $3^{\circ}$ ano do Ensino Médio estabelecem com os saberes experienciados nas aulas de EF e suas implicações para a construção das identidades desse componente curricular. Para tanto, buscamos alternativas que potencializassem e expressassem as aprendizagens na mediação entre o falar de e o fažer com, valorizando o modo como o aluno se relaciona com o saber, produzindo sentidos às experiências com a EF durante a escolarização, por meio de narrativas autobiográficas e imagéticas.

Os alunos dividem o período de escolarização em três etapas (Ensino Fundamental I, Fundamental II e Médio). Cada etapa narrada deixa as pistas (Ginzburg, 1989) a respeito de como as identidades para a EF vão sendo construídas, desconstruídas e reconstruídas em um movimento histórico a partir das tensões provocadas por suas relações estabelecidas (i) com os 
saberes compartilhados na disciplina, (ii) com a lógica escolar, (iii) com os professores e (iv) com as práticas de ensino.

Os resultados apontam um movimento histórico imbricado entre as experiências dos estudantes com as aulas e as identidades criadas por eles para a disciplina, que se inicia a partir das primeiras séries do Ensino Fundamental, quando eles assemelham a disciplina a momentos de recreio e lazer.

No momento que a EF começa a se aproximar da lógica escolar de ensino, nas séries finais do Ensino Fundamental, com aulas em sala, conteúdos sistematizados em conceitos e enunciados e avaliações teóricas, começa um estranhamento nos estudantes em virtude do conflito da identidade criada para ela nas primeiras séries da escolarização, o que resulta em uma rejeição e atua como um dos fatores determinantes no afastamento dos alunos das aulas. Já no Ensino Médio, os jovens entendem a EF novamente como um espaço de laz̧er e de descanso, uma espécie de "válvula de escape" das outras disciplinas, tidas como importantes para o momento da vida em que estão atravessando.

Compreendemos que os processos identitários que atravessam a EF são tensionados por diversos fatores ligados intrinsecamente às experiências dos alunos com o conteúdo da disciplina dentro e fora da escola. A relação que os alunos desenvolvem com os saberes compartilhados com a disciplina são determinantes para a criação dessas identidades, as quais, por sua vez, influenciam diretamente naquilo que o estudante escolhe ou não aprender nos anos seguintes.

\section{Referências}

Backes, J. L. (2018). Juventudes e Ensino Médio: tensões e disputas pelos sentidos. Acta Scientiarum: Education, 40(2), 1-13. doi:10.4025/actascieduc.v40i2.38320

Brandolin, F., Koslinski, M., \& Soares, A. J. G. (2015). A percepção dos alunos sobre a educação física no ensino médio. Journal of Physical Education, 26(4), 601-610. doi:10.4025/reveducfis.v26i4.29836

Carrano, P. C. R. (2003). Juventudes e cidades educadoras. Petrópolis: Vozes.

Charlot, B. (2000). Da relação com o saber: elementos para uma teoria. Porto Alegre: Artmed. 
Charlot, B. (2009). Ensinar a educação física ou ajudar o aluno a aprender o seu corpo-sujeito. In H. S. Dantas Jr., R. Kuhn, \& S. D. Ribeiro (Orgs.), Educação Física, esporte e sociedade: temas emergentes (Vol. 3, pp. 231-246). São Critóvão: Editora da UFS.

Dewey, J. (1978). Vida e educação (11a ed.). São Paulo: Editora Melhoramentos.

Duarte, C. P., \& Mourão, L. (2007). Representações de adolescentes femininas sobre os critérios de seleção utilizados para a participação em aulas mistas de educação física. Movimento, 13(1), 37-56. doi:10.22456/1982-8918.2924

Fabri, E. I., Rossi, F., \& Ferreira, L. A. (2016). Episódios marcantes das aulas de educação física: valorizando as experiências dos alunos por meio de narrativas. Movimento, 22(2), 583-595. doi:10.22456/1982-8918.56785

Falcão, J. M., Ventorim, S., Santos, W., \& Ferreira Neto, A. (2012). Saberes compartilhados no ensino de jogos e brincadeiras: maneiras/artes de fazer na educação física. Revista Brasileira de Ciências do Esporte, 34(3), 615-631. doi:10.1590/S0101-32892012000300007

Gil-Madrona, P., Cachón-Zagalaz, J., Diaz-Suarez, A., Valdivia-Moral, P., \& Zagalaz-Sánchez, M. L. (2014). Las niñas también quieren jugar: la participación conjunta de niños y niñas en actividades físicas no organizadas en el contexto escolar. Movimento, 20(1), 103-124. doi:10.22456/1982-8918.38070

Ginzburg, C. (1989). Mitos, emblemas, sinais: morfologia e história. São Paulo: Companhia das Letras. Hall, S. (2000). Quem precisa de identidade? In S. Hall \& K. Woodward, Identidade e diferença: a perspectiva dos estudos culturais (Org. T. T. Silva, pp. 103-133). Petrópolis: Vozes.

Hébrard, J. (1990). A escolarização dos saberes elementares na época moderna. Teoria \& Educação, (2), 65-107.

Najmanovich, D. (2001). O sujeito encarnado. Rio de janeiro: DP\&A.

Neira, M. G., \& Nunes, M. L. F. (2009). Educaşão física, currículo e cultura. São Paulo: Phorte.

Pereira, B. P., \& Lopes, R. E. (2016). Por que ir à escola? Os sentidos atribuídos pelos jovens do Ensino Médio. Educaşão \& Realidade, 41(1), 193-216. doi:10.1590/2175-623655950

Pérez, C. L. V., Tavares, M. T. G., \& Araújo, M. S. (2009). Memórias e patrimônios: experiências em formação de professores. Rio de Janeiro: EdUERJ. 
Reis, R. (2012). Experiência escolar de jovens/alunos do Ensino Médio: os sentidos atribuídos à escola e aos estudos. Educação e Pesquisa, 38(3), 637-652. doi:10.1590/S151797022012000300007

Santos, V. F., Vieira, A. O., Mello, A. S, Schneider, O., Ferreira Neto, A. F., \& Santos, W. (2014). Educação física e o processo de escolarização: uma análise sob a perspectiva do aluno. Journal of Physical Education, 25(4), 539-553. doi:10.4025/reveducfis.v25i3.23566

Santos, W., Paula, S. C., Matos, J. M. C., Frossard, M. L., Schneider, O., \& Ferreira Neto, A. (2016). A relação dos alunos com os saberes nas aulas de educação física. Journal of Physical Education, 27(1), e2737. doi:10.4025/jphyseduc.v27i1.2737

Schneider, O., \& Bueno, J. G. S. (2005). A relação dos alunos com os saberes compartilhados nas aulas de educação física. Movimento, 11(1), 23-45. doi:10.22456/1982-8918.2860

Souza, E. C. (2006). A arte de contar e trocar experiências: reflexões teórico-metodológicas sobre história de vida em formação. Revista Educação em Questão, 25(11), 22-39. Recuperado de https://periodicos.ufrn.br/educacaoemquestao/article/view/8285/5958

Vieira, A. O., Santos, W., \& Ferreira Neto, A. (2012). Tempos de escola: narrativas da formação discente ao ofício docente. Movimento, 18(3), 119-139. doi:10.22456/1982-8918.28131

Würdig, R. C. (2010). Recreio: os sentidos do brincar do ponto de vista das crianças. InterMeio: Revista do Programa de Pós-Graduação em Educação, 16(32), 90-105. Recuperado de https://periodicos.ufms.br/index.php/intm/article/view/2427

\section{Referências consultadas}

Certeau, M. (2014). A invenção do cotidiano: artes de fazer (22a ed.). Petrópolis: Vozes.

Charlot, B. (Org.). (2001). Os jovens e o saber: perspectivas mundiais. Porto Alegre: Artmed.

Submetido à avaliação em 10 de junho de 2019; revisado em 23 de outubro de 2019; aceito para publicação em 08 de novembro de 2019. 